\title{
Review
}

Intervirology

\section{West Nile Virus: The Complex Biology of an Emerging Pathogen}

\author{
Sebastian Ulbert \\ Vaccine Technologies Unit, Fraunhofer Institute of Cell Therapy and Immunology, Leipzig, Germany
}

\section{Key Words}

Flavivirus $\cdot$ Immunity $\cdot$ Vaccination $\cdot$ West Nile virus •

Zoonosis $\cdot$ Emerging pathogen

\begin{abstract}
West Nile virus (WNV) is a zoonotic virus that circulates in birds and is transmitted by mosquitoes. Incidentally, humans, horses and other mammals can also be infected. Disease symptoms caused by WNV range from fever to neurological complications, such as encephalitis or meningitis. Mortality is observed mostly in older and immunocompromised individuals. In recent years, epidemics caused by WNV in humans and horses have become more frequent in several Southern European countries, such as Italy and Greece. In 1999, WNV was introduced into the USA and spread over North America within a couple of years. The increasing number of WNV outbreaks is associated with the emergence of novel viral strains, which display higher virulence and greater epidemic potential for humans. Upon infection with WNV, the mammalian immune system counteracts the virus at several different levels. On the other side, WNV has developed elaborated escape mechanisms to avoid its elimination. This review summarizes recent findings in WNV research that help to understand the complex biology associated with this emerging pathogen.

Copyright $\odot 2011$ S. Karger AG, Basel
\end{abstract}

\section{Introduction}

In 1937 a virus was isolated from a patient with febrile illness in the West Nile District in Uganda and subsequently termed West Nile virus (WNV) [1]. It is a zoonotic pathogen, which mainly infects birds and is transmitted via mosquitoes. However, the insect vectors can also infect mammals such as humans or horses, where WNV can lead to fever and severe neurologic disease. During the decades following its first description, sporadic outbreaks of $\mathrm{WNV}$-associated disease were observed in Africa, Asia and around the Mediterranean Sea. In the last 15 years however, records of WNV outbreaks have increased, and up until today the virus has invaded almost all tropical and subtropical regions of the world. The spreading of WNV is considered to correlate with the emergence of novel, more pathogenic strains.

In humans, most infections with WNV remain asymptomatic, but $20 \%$ of the individuals develop flulike symptoms with high fever. First signs of disease are observed 2-14 days postinfection. In about $1 \%$ of the cases, WNV can lead to a severe neuroinvasive disease (encephalitis, meningitis or flaccid paralysis). Within this group the mortality rate can reach $20 \%$. In particular, older and immune-suppressed persons are at risk [2]. An infection with WNV is mostly transient and leaves a life-

\section{KARGER}

Fax +41613061234

E-Mail karger@karger.ch

www.karger.com
Sebastian Ulbert

Vaccine Technologies Unit

Fraunhofer Institute of Cell Therapy and Immunology, Perlickstrasse 1

DE-04103 Leipzig (Germany)

Tel. +49 34135536 2106, E-Mail Sebastian.ulbert@izi.fraunhofer.de 
long immunity. However, persistent infections have been demonstrated occasionally [3].

Horses are more likely to develop severe symptoms than humans, and mortality rates reach $40 \%$. Major clinical signs in infected horses are high fever, ataxia and encephalitis. Observation of equine populations might therefore be useful to predict WNV outbreaks among human communities [4].

\section{Transmission and Epidemiology}

Compared to most mosquito-borne viruses, WNV has an enormous vector and host range. More than 300 avian species are susceptible and many of these develop high viral serum titers during the acute phase of infection, most prominently passerine species such as house sparrows and crows [5]. During a time window of 3-7 days after infection these WNV titers are high enough to transmit the virus to blood-sucking mosquitoes and infect them. With few exceptions (alligators and certain frogs) such serum concentrations have been observed in birds only, hence the mammalian hosts provide a dead end for WNV. However, in rare cases, WNV transmission has been documented among humans via blood transfusion, via organ transplantation and via the intrauterine route [2]. As a consequence, in several countries blood donations from affected areas are screened for the presence of WNV nucleic acids.

Although WNV has been isolated from more than 60 mosquito species, the most important insect vectors are bird-feeding mosquitoes of the Culex genus. Depending on the geographic region, different species are responsible for transmission of the virus, such as C. pipiens and C. modestus in Europe or C. univittatus in Africa. In the USA, C. pipiens, C. tarsalis and C. quiquefasciatus dominate, depending on the area [6].

Especially in regions with moderate climate, vertical transmission and the ability of WNV to overwinter in hibernating mosquitoes might be of importance for the occurrence of epidemics in the following summer [7, 8]. The worldwide occurrence of Culex species in combination with a transmission via migratory birds allows WNV to potentially invade nearly all moderate and tropical regions in the world.

Since the 1960s, WNV has caused outbreaks of high fever and neurologic disease among humans or horses in Israel, India, South Africa and Southern Europe, with a tendency to more serious epidemics in the late 1990s [9]. In 1999, the virus came into the focus of public interest following its introduction into the USA. Starting from New York City, the epidemic spread over the entire continent within a few years and reached countries in Latin America. Sequence analyses of the WNV isolates circulating in the USA revealed that these were closely related to a strain responsible for a severe outbreak in Israel in 1999 , hence it is assumed that the viruses causing both epidemics had the same origin [10]. In the USA, almost 30,000 human cases were confirmed between 1999 and September 2010. These were associated with more than 1,100 deaths (http://www.cdc.gov/ncidod/dvbid/westnile/). In addition to humans, thousands of horses were affected, and high mortality rates were reported.

WNV had not caused severe mortality in birds until the late 1990s. However, from 1998 onwards, avian mortality was associated with outbreaks in Israel [11] and with the epidemic in the USA. Here, WNV has led to a dramatic decrease in the populations of many American bird species [12], and bird mortality is seen as an important indicator for WNV circulation. In recent years, WNV infections became more frequent in European countries, such as Hungary and Italy [13]. In 2010, major outbreaks occurred in Romania and Greece [14, 15]. In the same year, WNV cases were also reported from Russia, Italy, Turkey, Israel and Morocco.

Taken together, these data demonstrate the spreading of WNV and imply the occurrence of novel WNV variants over the last 15 years with increased virulence and epidemic potential both for birds and for mammals.

\section{Structure and Replication}

WNV belongs to the genus Flavivirus, which consists of more than 70 viruses. Among these are several arthropod-transmitted viruses with clinical importance, most prominently dengue virus (DENV), yellow fever virus (YFV), tick-borne encephalitis virus (TBEV) and Japanese encephalitis virus (JEV). Flaviviruses cause severe health problems in nearly all parts of the world. Within flaviviruses, WNV is classified into the in JEV serogroup, including also Murray Valley encephalitis virus (MVEV), St. Louis encephalitis virus (SLEV) and Usutu virus (USUV). Phylogenetic analyses have revealed that most $\mathrm{WNV}$ isolates can be assigned to two lineages [16]. Lineage 1 consists of isolates from North Africa, Europe, Israel and USA, with sub-lineages in India and Australia (Kunjin virus). Lineage 2 comprises isolates from West, Central, East and South Africa including Madagascar, but is recently also found in Europe (see below). The two 
lineages share approximately $75 \%$ identity on the RNA level and approximately $94 \%$ identity on the amino acid level. There is also evidence for the existence of novel WNV lineages which are distinct from lineage 1 and 2 [e.g. 17].

Flaviviruses have a spherical structure of approximately $50 \mathrm{~nm}$ diameter, consisting of the nucleocapsid which is surrounded by a membrane envelope. Two structural transmembrane proteins are found in the virion, the envelope protein (E) and the membrane protein prM. E has major roles in the viral life cycle (receptor interaction, membrane fusion and virion assembly), and prM stabilizes the conformation of $\mathrm{E}$ during virion assembly [18]. The nucleocapsid protein $\mathrm{C}$ encloses the WNV genome of 11.7 kilobases single-stranded positive-polarity RNA, which is translated into a single polypeptide upon infection of the host cell. This polyprotein is enzymatically processed by both viral and host cell proteases, yielding the three structural proteins $(\mathrm{C}, \mathrm{prM}$ and $\mathrm{E})$ and seven non-structural proteins (NS1, 2A, 2B, 3, 4A, 4B and 5), as illustrated in figure 1 . The non-structural proteins (NSPs) mediate processes of intracellular viral replication, such as RNA replication, translation and RNA packaging. For some NSPs a clear function could be demonstrated, whereas for others the exact roles in replication remains to be determined. NS5 represents the RNA-dependent RNA polymerase activity. NS3 was shown to act as helicase and serine protease. The complex of the NS2B and NS3 proteins processes the polyprotein at several sites to liberate NSPs and to generate mature C protein [19]. NS4A induces membrane rearrangements associated with WNV infection [20]. The glycosylated NS1 protein is secreted by infected cells and also associates with the cell surface [21]. Its function is unclear, however it is a target for protective antibodies, as discussed below. A variant of NS1 is the protein NS1', which has a C-terminal extension resulting from a -1 ribosomal frameshift event near the beginning of the NS2A coding sequence. There is evidence that NS1' is involved in neuroinvasiveness of WNV and the other members of the JEV serogroup [22].

Upon injection by the biting insect vector, WNV is believed to first infect dendritic cells in the skin. These cells transport the virus to draining lymph nodes, which leads to the spread of WNV to the bloodstream and peripheral organs. After a period of approximately 1 week the virus enters the central nervous system (CNS), and at the same time viremia in serum ceases. Several mechanisms for crossing the blood-brain barrier (BBB) have been suggested for flaviviruses, such as an increase in the barrier's permeability by local production of TNF- $\alpha$, en-

West Nile Virus: The Complex Biology of an Emerging Pathogen try after disruption of the $\mathrm{BBB}$ or direct axonal transport of the virus via peripheral neurons [23].

$\mathrm{WNV}$ was shown to interact with the surface C-type lectins DC-SIGN and DC-SIGNR present on some dendritic cells and macrophages, suggesting that these molecules serve as attachment receptors for the virus [24]. Both molecules were reported to be expressed on microvascular endothelial cells at the BBB, hence they could be involved in CNS invasion by WNV [25]. In addition, the $\alpha v \beta_{3}$ integrin was found to mediate WNV entry [26], however, the virus can infect cells in its absence [24]. Hence, receptors on all different cell types infected by WNV still have to be determined.

Following attachment to the cellular surface, WNV enters the cells via endocytosis. In the endosome, the $\mathrm{E}$ protein undergoes substantial structural changes, leading to the exposure of a specific part of $\mathrm{E}$ (the fusion peptide) and its insertion into the host membrane. After membrane fusion, the capsid and subsequently viral RNA are released into the cytosol and the synthesis of the polyprotein is initiated.

Flaviviruses induce dramatic changes in the morphology of intracellular membranes, a common phenomenon of positive-sense RNA viruses. Viral proteins and RNA accumulate in structures termed replication complexes (RCs) that are surrounded by host membranes. The NS4A protein plays a major role in this process as expression of the protein in the absence of flaviviral infection induces similar membrane rearrangements [20]. Recent studies using 3D modeling of electron tomograms from infected cells revealed insight into the structure of the RCs of $\mathrm{WNV}$ [27]: the viral replication machinery is enveloped by host membranes sequestered from an early stage within the secretory pathway, and the RCs reside at invaginations of the endoplasmic reticulum (ER). Small channels or pores mediate free access of the replication machinery to the cytosol, enabling the exchange of e.g. RNA and nucleotides. RNA found in the RCs is mostly doublestranded. As dsRNA is an intermediate in flavivirus RNA replication, this indicates that synthesis of viral RNA takes place at the RCs. On the other hand, this finding also suggests a role of the membrane wrapping in shielding viral replication from cytosolic host cell molecules that detect dsRNA. Thereby, the innate antiviral response is inhibited, which is usually triggered by the detection of dsRNA in the cell [28].

The newly synthesized RNA associates with the C protein in the cytosol and forms the nucleocapsid, which then buds into the lumen of the ER. Upon budding, the two viral structural membrane proteins $\mathrm{E}$ and prM, 
which are present as heterodimers in the ER membrane, form the envelope around the capsid. Virions are then transported along the secretory pathway where maturation of the virus occurs. A key event is the furin-mediated cleavage of the prM protein into pr and M [29], leading to the release of the pr-fragment. Subsequently, M and E heterodimers dissociate, $\mathrm{E}$ forms homodimers and the mature virions leave the cell.

Many host cell proteins, e.g. proteases, are sequestered by WNV to function in several aspects of its life cycle. RNAi screenings of WNV-infected human HeLa cells identified hundreds of proteins with potential roles in WNV replication, and these belong to very diverse pathways [30]. Hence, we are only beginning to unravel all the consequences of a WNV infection for the host cell.

\section{Occurrence of Novel Virulent WNV Strains}

Similar to other single-stranded RNA viruses, the WNV genome is evolving rapidly. Mutations occur primarily via errors made by the RNA-dependent RNA polymerase. As a consequence, novel variants with greater epidemic potential emerge and spread, e.g. by displaying more efficient replication in birds or better transmission by the insect vector $[31,32]$.

So far, mostly WNV strains from lineage 1 have caused epidemics with fatalities in humans or horses, whereas lineage 2 strains were believed to be less pathogenic and virulent. However, this view is changing dramatically. In South Africa, also lineage 2 viruses were recently associated with neurologic disease [33]. Moreover, the WNV strains causing the 2010 outbreaks in Greece and Russia both belong to lineage 2 [14].

Several mutations in the WNV genome can be linked to the emergence of virulent WNV strains in both lineages. A single $\mathrm{N}$-linked glycosylation motif within the $\mathrm{E}$ protein can influence the virulence of the virus. Occurrence of this NYS sequence at positions 154-156 makes the virus significantly more pathogenic for mice [34]. Similar results were also reported for birds, and the increased viremia was attributed to increased heat stability of the glycosylated E protein [35]. Highly virulent lineage 1 strains (such as the isolates from New York 1999) have this motif, whereas it is absent from less virulent lineage 1 strains, such as the Kunjin virus, and many of the lineage 2 strains. Importantly, this motif is present in most of the recently identified highly virulent lineage 2 strains [33].
After the first years of the North American epidemic, the dominating strain (NY1999) was replaced by a novel variant (WN02), characterized by another mutation in the E protein, V159A. Compared to NY1999, this strain replicates more efficient at higher temperature in the mosquito vector [36].

Another critical residue is found within the NS3 protein. WNV strains of lineage 1 with a threonine at position 249 display low pathogenicity in birds. In contrast, a proline at this position renders the virus significantly more virulent [32]. The 249 residue is located in the RNA helicase domain, and the T249P mutation might allow for more effective viral replication at higher temperatures. This is of clear advantage for a virus replicating in birds. The T249P mutation has emerged on several occasions independently, every time associated with severe disease symptoms in humans. Most recently, this mutation was identified in the lineage 1 strain circulating in Northern Italy [13].

Other amino acid substitutions, which turn low pathogenic WNV strains into more virulent ones, increase the capability of the virus to escape the vertebrate immune responses, as discussed below.

It is evident from the epidemiological data obtained over the last decades that WNV strains with increased virulence for birds and mammals are emerging. Due to the omnipresence of suitable mosquito vectors and by infecting migratory birds, these novel variants can rapidly spread to new locations. The occurrence of virulent strains in both major lineages is also a challenge for the development of specific diagnosis and preventive tools, such as vaccines.

\section{Immune Responses to WNV}

The vertebrate immune system is well prepared to meet viral pathogens. Innate, humoral and cellular immune responses are all active against WNV, as has been determined primarily in rodent models. On the other side, the virus possesses several mechanisms to escape its elimination.

\section{Innate Response}

Especially in a primary infection innate immune responses are essential for the control of WNV. As a first line of defense, the host cell senses the presence of the virus via pathogen recognition receptors (PRRs) and then activates 
effector proteins which attack different mechanisms of the viral replication machinery. PRRs are proteins such as the toll-like receptors (TLRs), which detect virus-specific structures like dsRNA or other non-self nucleic acid species. Upon binding to their specific ligands, PRRs start the antiviral response by inducing class I interferons (IFN- $\alpha$ and $-\beta$ ) via different signaling pathways. Class I interferons are secreted and bind to cell surface receptors, either in an autocrine or paracrine way, thereby activating Janus kinase-signal transducer and activator of transcription (JAK-STAT) signal transduction. As a consequence, hundreds of interferon-stimulated genes (ISGs) are transcribed, including several antiviral effector molecules.

A potent and rapid IFN-I response was shown to be essential for the successful control of a WNV infection $[37,38]$. Experiments in cells lacking specific parts of the innate response identified RIG-1 and MDA-5 as important PRRs for WNV. They are involved in the initiation and the maintenance of the IFN-I response, respectively [39]. Both proteins are activated by the presence of viral RNA in the cytosol and induce IFN-I production via signaling cascades. Upon RIG-1 or MDA-5 activation, signaling occurs via the adaptor molecule IPS- 1 . This leads to activation of the transcription factors IRF-3 or IRF-7. These proteins mediate the transcription of IFN-I genes and are required for the control of a WNV infection. However, their relative contribution to IFN-I production after WNV infection seems to be cell type specific [40]. The lack of IPS-1 in an infection with WNV leads to an uncontrolled inflammatory response. IPS-1-deficient mice show increased production of non-neutralizing antibodies, increased numbers of virus-specific CD8+ T cells and non-specific immune cell proliferation. In addition, WNV enters the CNS earlier and replicates more efficiently, leading to higher lethality compared to wildtype animals. Hence, IPS-1 plays a central role in coordinating the immune responses against WNV [41].

A recent study demonstrated a role for caspase-12 in regulating RIG-I activity. Caspase-12 is a protease with functions in apoptotic and inflammatory signaling pathways and is a known attenuator of innate responses to several bacterial infections. In contrast, caspase-12-deficient mice are more susceptible to WNV and display higher viral load in the CNS [42], indicating a positive role of this protein in antiviral responses. Indeed, it was found that caspase- 12 regulates ubiquitination of RIG-1 via the E3 ubiquitin ligase TRIM25, which is essential for initiating further antiviral signals.

In addition to RIG-1 and MDA-5, TLR-3 and TLR-7 have been shown to be involved in the response to a WNV infection. Both proteins are expressed on the cell surface and in endosomes. TLR-3 senses dsRNA and activates IRF-3/IRF-7 via its adaptor molecule TRIF. Its role in protection against WNV seems to be dominant in the brain, but has been discussed controversially: one study showed increased resistance and another increased susceptibility to the virus in the absence of TLR-3 [43, 44]. Differential experimental settings (such as virus passage history or inoculation route) might account for this contradiction [44]. TLR-7 recognizes uridine and guanosine-rich ssRNA. TLR-7 and its adaptor molecule MyD88 are required for an effective response against WNV [45]. The proteins apparently have a major role in homing of leukocytes to sites of WNV infection, a process which is dependent on the cytokine IL-23. The fact that IFN-I levels in the blood after WNV challenge were higher in the absence of TLR-7 than in wild-type mice supports the assumption that several distinct PRRs function in the defense against WNV and display a certain degree of redundancy.

Several interferon-induced antiviral effector proteins have been analyzed for a role in the control of WNV infections. These proteins directly block virus replication by interference with viral and cellular translation. The dsRNA-activated protein kinase $(\mathrm{Pkr})$ and the RNaseL/2',5'-oligoadenylate synthetase (OAS) were shown to be critical. Mice lacking these proteins display higher susceptibility to the virus than wild-type animals [46]. Moreover, polymorphisms in the OAS1 gene are associated with susceptibility to WNV infections in humans and in horses [47].

Natural killer (NK) cells are specialized in recognizing and killing of virus-infected cells. Recently, it has been shown that NK cells recognize the $\mathrm{E}$ protein of $\mathrm{WNV}$ via their receptor molecule NKp44, which is only present on activated NK cells and involved in triggering their cytolytic activity [48]. However, WNV infection is associated with the upregulation of MHC class I molecules [49]. As MHC class I molecules represent an inhibitory signal for NK cells, their upregulation is a widespread strategy of pathogens to escape NK cell-mediated lysis. On the other hand, an increase in MHC class I molecules on the cellular surface leads to increased recognition and killing of the infected cell by CD8+ T cells in later stages of the infection. It seems that WNV counteracts NK cell activity in early stages of infection at the price of being more vulnerable to cytotoxic T cells (CTL) later on. This might indicate the need of WNV to efficiently escape the innate immune response in order to quickly establish a high-level viremia in the blood, suitable for the transmission to the mosquito vector [48]. 
Another important component of the innate immune response against WNV is the complement system. Complement is an important primary defense and a clearance mechanism for both the innate and adaptive immune responses. It consists of several distinct proteins that function in the form of enzyme cascades. Complement finally acts through opsonization and direct lysis of pathogens, or through effects on cellular and humoral adaptive responses. The complement cascades can be activated via three different pathways, termed classical, mannanbinding and alternative. Initiation of the classical pathway is through binding of the complement protein Clq to antigen-antibody complexes or to the pathogen surface. The mannan-binding pathway is activated by interaction of lectins, such as the mannose-binding lectin (MBL), with microbial sugar moieties. The alternative pathway is started by the spontaneous proteolysis of the complement factor $\mathrm{C} 3$ to $\mathrm{C} 3 \mathrm{~b}$ which then binds to membranes of viruses or cells, mediating their destruction. Mice deficient in C1q, C3 or other complement components of all three activation pathways show increased viral load in the CNS upon WNV infection and enhanced lethality [50]. MBL directly binds the surface of flaviviruses via terminal mannose containing carbohydrate ligands, and virus neutralization is achieved by inhibiting viral fusion with the host cell membrane. In case of WNV, MBL-mediated neutralization only occurs with insect cell-derived virus, indicating different glycosylation patterns of $\mathrm{WNV}$ virions in vertebrates and insects [51].

\section{Inhibition of the Innate Response by WNV}

It is known for flaviviruses that the antiviral effects of IFN-I are most effective at early stages of infection, and that they become less effective when an infection is already established, which indicates active countermeasures undertaken by the virus [52]. There is increasing evidence that WNV interferes with the innate immune system. As described below, inhibition of the IFN-I response by WNV occurs at several distinct points, e.g. via masking the viral dsRNA from cytosolic PRRs, or via antagonizing effects of viral proteins on specific components of the innate signal transduction cascades. In addition, it was shown recently that several viruses, including $\mathrm{WNV}$, use 2'-O-methylation of the $5^{\prime}$ cap structures in their RNAs to mimic cellular mRNAs and thereby hide from components of the innate immune system [53].

The activation of an IFN-I-dependent antiviral response against highly virulent WNV strains occurs rela- tively late (i.e. after viral replication has already started), as demonstrated by the late activation of IRF-3 [54]. This indicates that pathogenic WNV strains delay their detection by the PRRs, allowing the virus to establish the infection before the innate response is activated. The wrapping of the viral RNA RCs in cellular membranes and the interference of viral proteins with cellular factors that function upstream of IRF3 might be mechanisms for such an interference.

Several WNV proteins are capable of directly interfering with innate immune mechanisms (fig. 1). The NS2A protein inhibits transcription of the IFN- $\beta$ gene. This activity can be abolished by introducing the single A30P mutation in the protein. The resulting virus becomes susceptible to IFN-I, is highly attenuated and even serves as a strategy for immunizing mice against WNV [55].

The NS5 protein illustrates very well how the ability of WNV to disturb IFN-I signaling can be attributed to single mutations in the viral genome. NS5 from the virulent NY99 strain inhibits the IFN-I-dependent phosphorylation of STAT1, a protein of the JAK-STAT signal transduction pathway, which is a key component of the IFN I response [56]. Thereby, transcription of ISGs is impaired, leading to a better survival of WNV inside the host cell. In contrast, the NS5 from the less virulent Kunjin strain is only a poor inhibitor of STAT1 phosphorylation. The change of a single a mino acid (S653F) in the Kunjin strain towards the sequence of the NY99 strain results in a significantly increased inhibition of STAT1 phosphorylation and a higher resistance of the Kunjin virus against IFN I. JAK/STAT signaling is also disturbed by NS4B [57].

RIP-1 is a kinase functioning in both the TLR-3- and RIG-1-mediated pathways of viral recognition. Normally, RIP-1 gets ubiquitinated upon dsRNA detection and mediates the activation of the transcription factor NFKB. However, the WNV E protein inhibits the ubiquitination and therefore blunts the cellular response to dsRNA [58]. This effect of the E protein is not via direct binding to RIP-1, hence the exact mechanism still has to be elucidated. Only E protein derived from Drosophila (dipteran) cells, and not from a moth (lepidopteran) cell line is able to block the innate response. This implies the need for mosquito-specific glycosylation of the E protein and a role of this suppressive mechanism early during primary infection, when vector-derived virions are present.

The NS1 protein was shown to inhibit TLR-3-dependent IRF- 3 and TNF- $\alpha$ activation and IFN- $\beta$ transcription [59]. In contrast, no such inhibition was found by Baronti et al. [60]. Although different experimental con- 


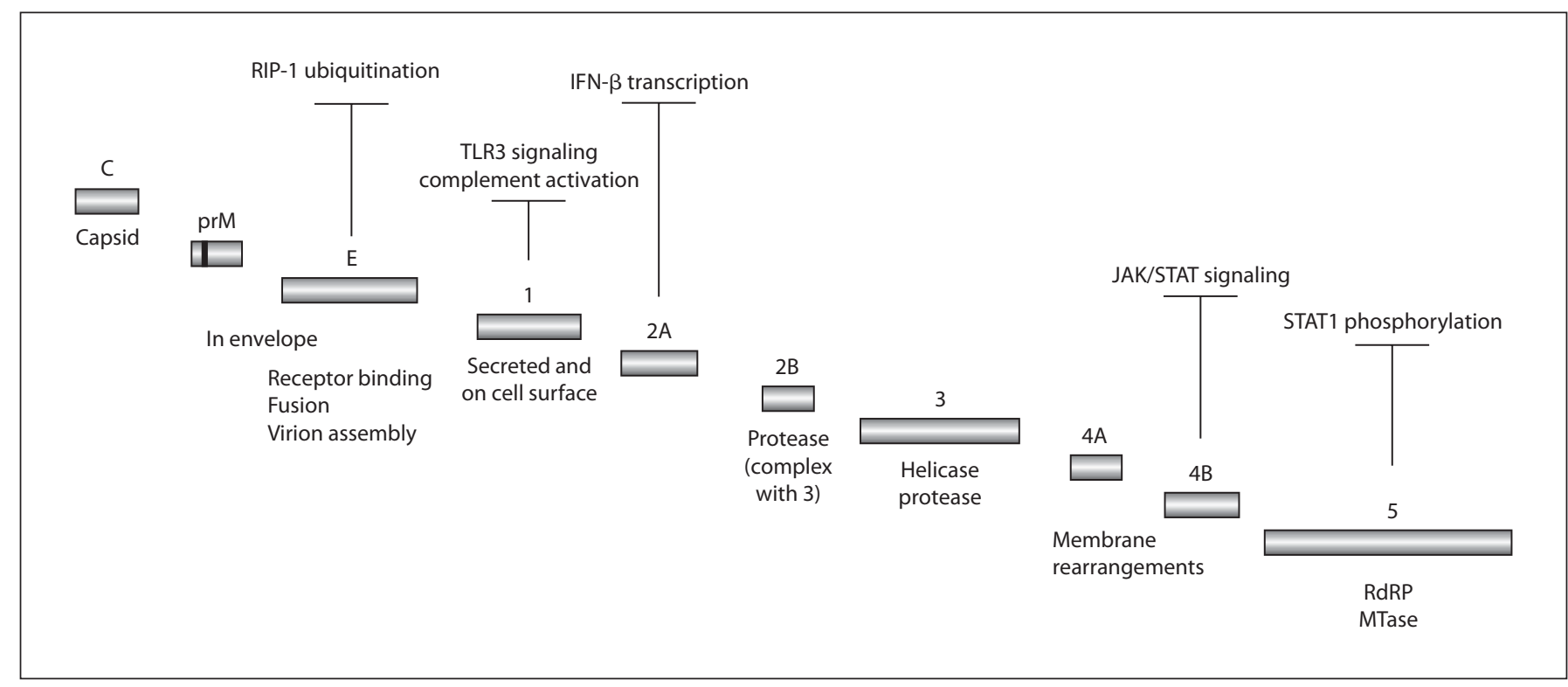

Fig. 1. WNV proteins and their roles in the viral life cycle (below) and in interference with the innate antiviral responses (on top). RdRP = RNA-dependent RNA polymerase; MTase = methyltransferase.

ditions and viral strains were used in the two conflicting studies, this issue remains to be clarified.

NS1 is also involved in counteracting destruction of WNV by the complement system via two distinct mechanisms: firstly, it binds to complement factor $\mathrm{H}$ and thereby reduces the alternative activation pathway [61]. Secondly, it interacts with complement factors C4 and C1s, thereby inhibiting the classical and the mannan-binding activation pathways [62].

In conclusion, WNV acquired several mechanisms to escape the innate immune response. The importance of the innate response is highlighted by the fact that efficient inhibition of IFN-I action usually is associated with virulence. Critical mutations in viral proteins that interfere with the IFN-I response, such as S653F in NS5, increase the resistance of the virus towards IFN-I-mediated response, leading to more virulent viruses.

It should be kept in mind that, despite of elaborate immune escape mechanisms and despite of the severe neurological symptoms potentially associated with infection, $\mathrm{WNV}$ is not able to establish a viremia in the mammalian blood which is comparable to the viremia reached in many bird species. Virus concentrations in the mammalian blood are not sufficient to infect mosquitoes and, therefore, mammals are dead-end hosts for the virus. Given the fact that infectious viremia is established within 3-7 days postinfection [5], it can be hypothesized that (at least in primary infections) innate immune mechanisms are critical for the transfer of WNV from the infected host to the mosquito vector. Although the avian innate immune system is far less well studied than the mammalian one, it is clear that basic mechanisms of antiviral defense, such as TLRs and effector proteins, are well conserved [63]. Still, there must be (even subtle) differences, because WNV evolved means to escape the avian innate response, but it is apparently less adapted to the mammalian one. A detailed study of the innate response against WNV in birds should give insight into mechanisms that are most critical for the control of a primary infection, both in birds and in mammals. It remains to be seen whether the recently emerging WNV strains with increased virulence will evolve mechanisms to evade the mammalian innate response more efficiently. The worrying consequence might then be that WNV replicates independently from birds.

\section{Humoral Response}

Several findings underline the importance of antibodies in the control of WNV: B-cell-deficient mice die after $\mathrm{WNV}$ infection but are protected after passive transfer of IgG [64]. Similarly, IgM-deficient mice die rapidly after $\mathrm{WNV}$ infection, indicating the requirement for IgM [65]. In addition, vaccination-induced protection correlates 
with neutralizing antibody titers [66]. The humoral response to a primary natural WNV infection is characterized by an early occurrence of IgM-dependent neutralizing antibodies. This early IgM response correlates with clearance of viremia in serum [65]. In contrast, neutralizing IgG appears rather late (after about 1 week), when peak viremia in serum is already over and WNV has entered the CNS [67]. This suggests a role for IgG in controlling WNV infections in the CNS, however the exact contribution of IgG to the clearance of primary infections remains to be determined.

Protective neutralizing antibodies are mainly directed against the E protein. The E protein consists of three distinct structural domains, DI, DII, DIII, involved in virion assembly, membrane fusion and receptor binding, respectively. All three domains contain epitopes for neutralizing antibodies, but DIII elicits the strongest neutralizing responses [67]. However, in human infections, most antibodies produced against the E protein are non-neutralizing or only poorly neutralizing and target DII [68]. The presence of non-neutralizing antibodies may lead to antibody-mediated enhancement (ADE) of infection, a phenomenon known primarily from DENV infections. ADE occurs when viruses are bound by non-neutralizing (or too few neutralizing) antibodies and efficiently enter new host cells via Fcy receptors on the cellular surface. The complement opsonin C1q is able to inhibit ADE by binding to specific anti-WNV IgG-subclasses. Clq reduces the number of antibodies that must bind the virion to neutralize WNV infectivity. Thereby, ADE becomes less likely as lower titers of neutralizing antibody are sufficient to block the infection [69]. This might be the reason why ADE has not yet been associated with human WNV cases.

In addition to E, also prM and NS1 were identified as targets for neutralizing antibodies. NS1 is a secreted and cell surface-bound protein, and the protective effect of antibodies against NS1 is dependent on Fcy receptors. This suggests that anti-NS1 antibodies bind to infected cells and mediate their phagocytosis and elimination by Fc $\gamma$-receptor-expressing phagocytes [70].

\section{Cellular Response - A Double-Edged Sword}

CTL recognize WNV antigens presented on MHCI molecules of infected cells, lyse these cells and secrete inflammatory cytokines [71]. The lytic activity of CTL is executed by perforin, granzymes A and B or Fas-Fas-ligand interactions.
Similar to antibodies, there is solid evidence that T-cell functions are required to control WNV infections: deficiencies in either CD4+ or CD8+ T cells are both associated with increased susceptibility to WNV in the mouse model $[72,73]$. Similar findings were obtained in mice with defects in the Fas or granule exocytosis (perforin and granzymes A and B) pathways [74]. In humans, impaired T-cell functions, e.g. due to cancer, lead to an increased risk for neurological infections [75]. All these deficiencies are associated with a significantly increased infiltration and persistence of WNV in the brain, hence a major role of T cells in controlling WNV seems to be the elimination of the virus in the CNS.

Upon infection with WNV, CD8+ T cells start to migrate into the CNS and elimination of the virus from the brain is initiated $[72,76]$. There are only limited numbers of immune cells in the CNS of healthy organisms, and $\mathrm{CD} 8+$ cells have to be attracted to neuronal tissues during a WNV infection. Chemokines such as CCL5 and its receptor CCR 5 have been implicated in this process. A deficiency in CCR 5 caused decreased migration of leukocytes to the CNS together with increased susceptibility to WNV [77]. The chemokine CXCL10 was also shown to recruit $\mathrm{CD} 8+\mathrm{T}$ cells and to be critical for controlling WNV in the brain [78]. CD40-CD40L interactions facilitate the passage of $\mathrm{T}$ cells through the $\mathrm{BBB}$ in response to a WNV infection [79].

The presence of CD8+ T cells in the CNS has been associated with protection due to viral clearance and with increased pathology due to immune-mediated damage of cells $[72,76]$. This discrepancy might be explained by the different levels of virulence of different WNV strains. For highly virulent strains with a highly destructive impact on neurons the $\mathrm{CD} 8+\mathrm{T}$-cell response in the brain is protective due to the need to efficiently eliminate infected cells. In contrast, during infections with less virulent strains, CD8+ T-cell actions become excessive and harmful [80].

In this context, it is interesting that the frequency of regulatory $\mathrm{T}$ cells (Tregs) is a predictive marker for the outcome of a WNV infection in humans and mice [81]. Tregs usually control cellular immune responses and particularly stop excessive actions of CD8+ T cells. A high level of Tregs is associated with asymptomatic WNV infections. In contrast, low frequency of Tregs, or even their absence, lead to increased virus load in the CNS and severe symptoms. Thereby, the levels of CD8+ T cells are inversely correlated to Tregs. This indicates that Tregs function in lowering WNV-associated disease symptoms by controlling excessive and potential harmful actions of $\mathrm{CD} 8+\mathrm{T}$ cells in the CNS. 
Mice deficient in CD4+ T cells are severely compromised in clearing WNV from the CNS and were more susceptible to the virus than wild-type animals. The lack of CD4+ T cells has a strong impact on late WNV-specific IgM and IgG levels, as well as on the activity of CD8+ cells in the CNS late in infection [73]. These results suggest an important role for $\mathrm{CD} 4+\mathrm{T}$ cells in assisting antibody production and maintaining CD8+ T-cell activation over time in a WNV infection.

To date, more than 200 epitopes associated with T-cell reactivity have been identified for $\mathrm{WNV}$, most of which are CD4+-specific [82]. These are found in structural proteins and NSPs. Epitopes recognized by human CTL have also been determined, with the E-protein-derived SVG9 peptide being a prominent one [83]. A DNA vaccine consisting of single-chain HLA-A2 MHC trimers and the SVG9 peptide protects $75 \%$ of HLA-A2 transgenic mice from lethal challenge with a highly virulent WNV strain [84]. This effect is independent of antibodies, highlighting the protective potential of $\mathrm{T}$ cells in WNV infections.

$\mathrm{T}$ cells are also involved in the age-related increase of severe symptoms during WNV infection, as was demonstrated in a rodent model. WNV-specific T cells from older mice have defects in cytokine and lytic granule production. Moreover, older CD4+ and CD8+ T cells fail to protect T-cell-deficient RAG1-/- mice against WNV after adoptive transfer, and also the traffic of $\mathrm{T}$ cells to the CNS is impaired in brains of older mice [85]. Hence, the effectiveness of T cells against a WNV infection decreases with age. This leads to increased susceptibility of the elderly, which underlines the need for the development of preventive actions.

\section{Vaccines}

Only veterinary WNV vaccines are currently on the market. Equine WNV vaccines in the USA led to a significant decrease in the number of severe clinical signs associated with WNV infections among horses [86].

Formalin-inactivated whole WNV particles are used to immunize horses and geese $[87,88]$. The basis of the other available vaccines are the prM and $\mathrm{E}$ proteins of virulent lineage 1 strains. Insertion of these two genes into the backbone of the yellow fever vaccine virus leads to a live attenuated chimeric flavivirus that was licensed for use in horses, and this system is now also being tested in humans [89]. Similarly, the genes for prM and E have been inserted into a canarypox vector. The resulting vi- rus is used to immunize horses [90]. In addition, prM/E is the basis for one of the first licensed DNA vaccines worldwide [91]. In all cases, a protective immune response is induced by the vaccine, but nevertheless annual re-vaccinations are generally recommended.

The role of different immune cells in vaccine-induced protection was analyzed in mice for the inactivated whole virus and the DNA vaccine [66]. Antibodies against the E protein are found to be most important for immune control. The role of CD8+ cells is dependent on the immunization schedule. After a single injection of the vaccine, CD8+ T cells are required for full protection. However, this requirement is lost if a booster injection is applied. These findings suggest a more supportive role of $\mathrm{CD} 8+\mathrm{T}$ cells in vaccine-induced immunity against WNV.

To date, there is no WNV vaccine available for humans. WNV affects older and immunocompromised people most severely. Live vaccines are not optimal for these individuals due to potential side effects, however several innovative inactive vaccination strategies are under development.

Recombinant E protein, mostly in combination with adjuvants, leads to the induction of highly neutralizing antibodies, and this strategy was used with the full protein, or with its domain DIII, expressed in Escherichia coli and insect cells $[92,93]$. The latter approach led to one of the most advanced vaccine candidates in humans [94]. As the protein is made in insect cells, the glycosylation pattern is expected to be similar to the one found on complete $\mathrm{WNV}$ virions after the passage through mosquitoes, which might help to induce an optimal antibody response.

As an alternative to using purified $\mathrm{E}$ protein alone, it was inserted into non-infectious subviral particles. These strategies led to promising results in rodent models. Domain DIII was chemically coupled to virus-like particles (VLPs) derived from the bacteriophage AP205, and the resulting structures confer protection to mice in the absence of adjuvants [95]. Retrovirus VLPs pseudotyped with the WNV E protein were shown to efficiently induce neutralizing antibodies [96]. In addition, insect cell-derived domain DIII was packaged into biodegradable nanoparticles together with CpG-motive containing oligonucleotides. The oligonucleotides serve as TLR-9 ligands, and a single immunization leads to the stimulation of potent T-cell responses. Protection using these nanoparticles is higher than in mice that received recombinant DIII protein absorbed to the adjuvant aluminum hydroxide [97]. 
These results show that, although recombinant E protein with adjuvant elicits protective immune responses, this can be further improved by using VLP- or nanoparticle-based technologies. The resulting vaccine candidates require only a single injection and/or do not need adjuvants.

Single-round infectious WNV particles are viruses with deletions in structural proteins such as the capsid. These particles are produced in packaging cells supplying the complete $\mathrm{C}$ protein. Upon infection, the particles enter cells and activate the immune system adequately, however, due to the absence of the genetic information for the complete $\mathrm{C}$ protein, no infectious viruses leave the cells. This immunization strategy has been successfully used in a primate model [98]. Similarly, WNV can be attenuated by targeted mutations and deletions within the coding sequence for the $\mathrm{C}$ protein, and these mutants elicit protection [99].

In recent last years, several WNV DNA vaccine candidates have been developed, and one has been licensed for use in horses. Expression of the prM/E proteins from the corresponding DNA plasmid leads to the formation of VLPs, which might help in stabilizing the antigens [91]. Safety testing of this vaccine was already conducted in humans [100]. Other recent DNA vaccine approaches against WNV use fusion of the antigen coding sequence to enhancer elements that stimulate the immune system, such as the complement protein C3d derivate P28 [101]. Similarly, co-administration of plasmids coding for specific cytokines, such as IL-15, can be used to increase the protective effect of a DNA vaccine [102].

An important advantage of DNA vaccines over recombinant subunit vaccines is that the antigen is produced by the immunized individual itself. Hence, viral proteins are presented to the immune system in their native conformation and with the correct modifications such as glycosylation patterns. With the development of novel delivery methods DNA vaccines are able to induce antigen-specific T- and B-cell responses similar to those elicited by live attenuated pathogens, usually in the absence of adjuvants [103]. In addition, DNA vaccines are flexible as they can be rapidly adapted to sequence variations of novel viral strains and do not require a cold chain, making them suitable for the use in tropical areas.

Combination of different vaccination strategies can lead to synergistic effects by simultaneous stimulation of different arms of the immune system. Our laboratory has recently shown that antibody responses against recombinant WNV E protein vaccines can be significantly opti- mized by a DNA-priming immunization. The level of neutralizing antibodies is significantly higher in mice after a heterologous prime boost compared to DNA- or protein-only vaccinated animals [104].

Until now almost all vaccine development was focused on protection against virulent lineage 1 strains, such as the New York 1999 viruses. Lineage 2 has so far not been associated with severe symptoms, and consequently cross-protection has not been investigated in all immunization approaches. However, the WNV genome appears to undergo rapid evolution, and the recent emergence of lineage 2 strains with high virulence in humans and horses will increase the demand for a WNV vaccine protecting against both major lineages and potential newly emerging WNV variants.

\section{Conclusions}

Two findings highlight the importance of WNV as an emerging zoonotic pathogen: firstly, worldwide reports of outbreaks are increasing in number. Secondly, these outbreaks are caused by novel strains with increased virulence.

Selection factors for mutations in the WNV genome which render viral strains more virulent include higher stability of the virion, e.g. at elevated temperatures, and efficient interference with the mammalian (and probably avian) IFN-I response. These mutations, in combination with its enormous vector and host range, enable the virus to rapidly spread and to become endemic in new locations.

In the vertebrate host, WNV meets an elaborated and efficient immune system. Especially in a primary infection, the innate immune response is considered to be the major force that controls viral dissemination. This is underlined by the fact that WNV has developed numerous mechanisms to interfere with the innate immune system at different levels.

In this context, some issues need to be addressed more intensively in the future. For example the immune response of birds to WNV, susceptible or resistant to severe symptoms, is still only poorly understood. As many bird species develop significantly higher viremia in the blood than mammals, it can be assumed that WNV blocks the avian immune system more efficiently than the mammalian one. It is important to find out the underlying mechanisms. A comparison of the avian target proteins involved with their mammalian homologues might enable the anticipation of mutations in the WNV genome 
which would make the virus more dangerous for humans.

Over the last decade, a lot has been learned about the biology of WNV, its replication and the immune response elicited by the virus. This knowledge needs now to be translated into efficient countermeasures, such as antiviral therapies or vaccines.

Especially for vaccinations, substantial progress has been made, with several vaccines being available in the veterinary sector and some promising candidates under development for the application in humans. However, $\mathrm{WNV}$ is a zoonotic virus circulating among a large pool of reservoir hosts. There is a continuous threat of the emergence of novel variants, and any countermeasures developed might have to be rapidly adapted in order to remain effective.

\section{Acknowledgements}

I thank Prof. Hermann Müller (Leipzig University), Drs Michael Szardenings, Sabine Breun, and Stefan Chabierski for critically reading the manuscript and for helpful discussions. I apologize to all authors whose work I was unable to cite because of space restrictions. Research in my laboratory is supported by the European Commission under FP7 (West Nile Shield Project: Epidemiology, Diagnosis and Prevention of West Nile Virus in Europe).

\section{References}

1 Smithburn KC, Hughes TP, Burke AW, Paul $\mathrm{JH}$ : A neurotropic virus isolated from the blood of a native of Uganda. Am J Trop Med Hyg 1940;20:471-472.

- 2 Hayes EB, Sejvar JJ, Zaki SR, Lanciotti RS, Bode AV, Campbell GL: Virology, pathology, and clinical manifestations of West Nile virus disease. Emerg Infect Dis 2005;11:11741179.

-3 Murray KO, Mertens E, Desprès P: West Nile virus and its emergence in the United States of America. Vet Res 2010;41:67.

4 Ward MP, Scheurmann JA: The relationship between equine and human West Nile virus disease occurrence. Vet Microbiol 2008;129: 378-383.

5 Komar N, Langevin S, Hinten S, Nemeth N, Edwards E, Hettler D, Davis B, Bowen R, Bunning $\mathrm{M}$ : Experimental infection of North American birds with the New York 1999 strain of West Nile virus. Emerg Infect Dis 2003;9:311-322.

6 Gubler DJ, Kuno G, Markoff L: Flaviviruses; in Knipe DM, Howley PM (ed): Fields Virology, ed 5. Philadelphia, Lippincott Williams \& Wilkins, 2007, pp 1155-1252.

-7 Miller BR, Nasci RS, Godsey MS, Savage HM, Lutwama JJ, Lanciotti RS, Peters CJ: First field evidence for natural vertical transmission of West Nile virus in Culex univittatus complex mosquitoes from Rift Valley Province, Kenya. Am J Trop Med Hyg 2000; 62:240-246.

8 Nasci RS, Savage HM, White DJ, Miller JR, Cropp BC, Godsey MS, Kerst AJ, Bennett P, Gottfried K, Lanciotti RS: West Nile virus in overwintering Culex mosquitoes, New York City, 2000. Emerg Infect Dis 2001;7:742-744.

-9 Hubálek Z, Halouzka J: West Nile fever - a reemerging mosquito-borne viral disease in Europe. Emerg Infect Dis 1999;5:643-650.
10 May FJ, Davis CT, Tesh RB, Barrett AD: Phylogeography of West Nile virus: from the cradle of evolution in Africa to Eurasia, Australia, and the Americas. J Virol 2011;85:29642974.

11 Bin H, Grossman Z, Pokamunski S, Malkinson M, Weiss L, Duvdevani P, Banet C, Weisman Y, Annis E, et al: West Nile fever in Israel 1999-2000: from geese to humans. Ann N Y Acad Sci 2001;951:127-142.

12 LaDeau SL, Kilpatrick AM, Marra PP: West Nile virus emergence and large-scale declines of North American bird populations. Nature 2007;447:710-713.

13 Barzon L, Franchin E, Squarzon L, Lavezzo E, Toppo S, Martello T, Bressan S, Pagni S, Cattai M, Piazza A, Pacenti M, Cusinato R, Palù G: Genome sequence analysis of the first human West Nile virus isolated in Italy in 2009. Euro Surveill 2009;14.

14 Papa A, Xanthopoulou K, Gewehr S, Mourelatos S: Detection of West Nile virus lineage 2 in mosquitoes during a human outbreak in Greece. Clin Microbiol Infect doi: 10.1111/j.1469-0691.2010.03438.x

15 Sirbu A, Ceianu CS, Panculescu-Gatej RI, Vazquez A, Tenorio A, Rebreanu R, Niedrig M, Nicolescu G, Pistol A: Outbreak of West Nile virus infection in humans, Romania, July to October 2010. Euro Surveill 2011;16.

16 Lanciotti RS, Ebel GD, Deubel V, Kerst AJ, Murri S, Meyer R, Bowen M, McKinney N, Morrill WE, et al: Complete genome sequences and phylogenetic analysis of West Nile virus strains isolated from the United States, Europe, and the Middle East. Virology 2002;298:96-105.

17 Vazquez A, Sanchez-Seco MP, Ruiz S, Molero F, Hernandez L, Moreno J, Magallanes A, Tejedor CG, Tenorio A: Putative new lineage of West Nile virus, Spain. Emerg Infect Dis 2010;16:549-552.
18 Guirakhoo F, Bolin RA, Roehrig JT: The Murray Valley encephalitis virus prM protein confers acid resistance to virus particles and alters the expression of epitopes within the R2 domain of E glycoprotein. Virology 1992;191:921-931.

19 Yamshchikov VF, Compans RW: Processing of the intracellular form of the West Nile virus capsid protein by the viral NS2B-NS3 protease: an in vitro study. J Virol 1994;68: 5765-5771.

20 Roosendaal J, Westaway EG, Khromykh A, Mackenzie JM: Regulated cleavages at the West Nile virus NS4A-2K-NS4B junctions play a major role in rearranging cytoplasmic membranes and Golgi trafficking of the NS4A protein. J Virol 2006;80:4623-4632.

21 Macdonald J, Tonry J, Hall RA, Williams B, Palacios G, Ashok MS, Jabado O, Clark D, Tesh RB, Briese T, Lipkin W: NS1 protein secretion during the acute phase of West Nile virus infection. J Virol 2005;79:1392413933.

22 Melian EB, Hinzman E, Nagasaki T, Firth AE, Wills NM, Nouwens AS, Blitvich BJ, Leung J, Funk A, et al: NS1' of flaviviruses in the Japanese encephalitis virus serogroup is a product of ribosomal frameshifting and plays a role in viral neuroinvasiveness. J Virol 2010;84:1641-1647.

23 Diamond MS, Mehlhop E, Oliphant T, Samuel MA: The host immunologic response to West Nile encephalitis virus. Front Biosci 2009; 14:3024-3034

24 Davis CW, Nguyen HY, Hanna SL, Sánchez MD, Doms RW, Pierson TC: West Nile virus discriminates between DC-SIGN and DCSIGNR for cellular attachment and infection. J Virol 2006;80:1290-1301. 
-25 Mukhtar M, Harley S, Chen P, BouHamdan M, Patel C, Acheampong E, Pomerantz RJ: Primary isolated human brain microvascular endothelial cells express diverse HIV/ SIV-associated chemokine coreceptors and DC-SIGN and L-SIGN. Virology 2002;297: 78-88.

$26 \mathrm{Chu} J J, \mathrm{Ng}$ ML: Interaction of West Nile virus with $\alpha_{\mathrm{v}} \beta_{3}$ integrin mediates virus entry into cells. J Biol Chem 2004;279:54533-54541.

-27 Gillespie LK, Hoenen A, Morgan G, Mackenzie JM: The endoplasmic reticulum provides the membrane platform for biogenesis of the flavivirus replication complex. J Virol 2010; 84:10438-10447.

28 Hoenen A, Liu W, Kochs G, Khromykh AA, Mackenzie JM: West Nile virus-induced cytoplasmic membrane structures provide partial protection against the interferon-induced antiviral MxA protein. J Gen Virol 2007;88:3013-3017.

-29 Stadler K, Allison SL, Schalich J, Heinz FX: Proteolytic activation of tick-borne encephalitis virus by furin. J Virol 1997;71:8475-8481.

-30 Krishnan MN, Ng A, Sukumaran B, Gilfoy FD, Uchil PD, Sultana H, Brass AL, Adametz R, Tsui M, Qian F, Montgomery RR, Lev S, Mason PW, Koski RA, Elledge SJ, Xavier RJ, Agaisse H, Fikrig E: RNA interference screen for human genes associated with West Nile virus infection. Nature 2008;455:242-245.

- 31 Davis CT, Ebel GD, Lanciotti RS, Brault AC, Guzman H, Siirin M, Lambert A, Parsons RE, Beasley DW, et al: Phylogenetic analysis of North American West Nile virus isolates, 2001-2004: evidence for the emergence of a dominant genotype. Virology 2005;342: 252-265.

-32 Brault AC, Huang CY, Langevin SA, Kinney RM, Bowen RA, Ramey WN, Panella NA, Holmes EC, Powers AM, Miller BR: A single positively selected West Nile viral mutation confers increased virogenesis in American crows. Nat Genet 2007;39:1162-1166.

- 33 Botha EM, Markotter W, Wolfaardt M, Paweska JT, Swanepoel R, Palacios G, Nel LH, Venter M: Genetic determinants of virulence in pathogenic lineage 2 West Nile virus strains. Emerg Infect Dis 2008;14:222-230.

- 34 Beasley DW, Whiteman MC, Zhang S, Huang CY, Schneider BS, Smith DR, Gromowski GD, Higgs S, Kinney RM, Barrett AD: Envelope protein glycosylation status influences mouse neuroinvasion phenotype of genetic lineage 1 West Nile virus strains. J Virol 2005;79:8339-8347.

- 35 Murata R, Eshita Y, Maeda A, Maeda J, Akita S, Tanaka T, Yoshii K, Kariwa H, Umemura T, Takashima I: Glycosylation of the West Nile virus envelope protein increases in vivo and in vitro viral multiplication in birds. Am J Trop Med Hyg 2010;82:696-704.

- 36 Kilpatrick AM, Meola MA, Moudy RM, Kramer LD: Temperature, viral genetics, and the transmission of West Nile virus by Culex pipiens mosquitoes. PLoS Pathog 2008; 4:e1000092.
7 Samuel MA, Diamond MS: Alpha/beta interferon protects against lethal West Nile virus infection by restricting cellular tropism and enhancing neuronal survival. J Virol 2005;79:13350-13361.

- 38 Keller BC, Fredericksen BL, Samuel MA, Mock RE, Mason PW, Diamond MS, Gale M Jr: Resistance to $\alpha / \beta$ interferon is a determinant of West Nile virus replication fitness and virulence. J Virol 2006;80:9424-9434.

39 Fredericksen BL, Keller BC, Fornek J, Katze MG, Gale M Jr: Establishment and maintenance of the innate antiviral response to West Nile virus involves both RIG-I and MDA5 signaling through IPS-1. J Virol 2008; 82:609-616.

40 Daffis S, Suthar MS, Szretter KJ, Gale M Jr, Diamond MS: Induction of IFN- $\beta$ and the innate antiviral response in myeloid cells occurs through an IPS-1-dependent signal that does not require IRF-3 and IRF-7. PLoS Pathog 2009;5:e1000607.

41 Suthar MS, Ma DY, Thomas S, Lund JM, Zhang N, Daffis S, Rudensky AY, Bevan MJ, Clark EA, Kaja MK, et al: IPS-1 is essential for the control of West Nile virus infection andimmunity. PLoS Pathog 2010;6:e1000757.

42 Wang P, Arjona A, Zhang Y, Sultana H, Dai J, Yang L, LeBlanc PM, Doiron K, Saleh M, Fikrig E: Caspase-12 controls West Nile virus infection via the viral RNA receptor RIG-I. Nat Immunol 2010;11:912-919.

43 Wang T, Town T, Alexopoulou L, Anderson JF, Fikrig E, Flavell RA: Toll-like receptor 3 mediates West Nile virus entry into the brain causing lethal encephalitis. Nat Med 2004; 10:1366-1373.

-44 Daffis S, Samuel MA, Suthar MS, Gale M Jr, Diamond MS: Toll-like receptor 3 has a protective role against West Nile virus infection. J Virol 2008;82:10349-10358.

45 Town T, Bai F, Wang T, Kaplan AT, Qian F, Montgomery RR, Anderson JF, Flavell RA, Fikrig E: Toll-like receptor 7 mitigates lethal West Nile encephalitis via interleukin 23-dependent immune cell infiltration and homing. Immunity 2009;30:242-253.

46 Samuel MA, Whitby K, Keller BC, Marri A, Barchet W, Williams BR, Silverman RH, Gale M Jr, Diamond MS: PKR and RNase L contribute to protection against lethal West Nile virus infection by controlling early viral spread in the periphery and replication in neurons. J Virol 2006;80:7009-7019.

-47 Rios JJ, Fleming JG, Bryant UK, Carter CN, Huber JC, Long MT, Spencer TE, Adelson DL: OAS1 polymorphisms are associated with susceptibility to West Nile encephalitis in horses. PLoS One 2010;5:e10537.

48 Hershkovitz O, Rosental B, Rosenberg LA, Navarro-Sanchez ME, Jivov S, Zilka A, Gershoni-Yahalom $\mathrm{O}$, Brient-Litzler E, et al: NKp44 receptor mediates interaction of the envelope glycoproteins from the West Nile and dengue viruses with NK cells. J Immunol 2009; 183:2610-2621.
49 King NJ, Kesson AM: Interferon-independent increases in class I major histocompatibility complex antigen expression follow flavivirus infection. J Gen Virol 1988;69:25352543.

50 Mehlhop E, Diamond MS: Protective immune responses against West Nile virus are primed by distinct complement activation pathways. J Exp Med 2006;203:1371-1381.

51 Fuchs A, Lin TY, Beasley DW, Stover CM, Schwaeble WJ, Pierson TC, Diamond MS: Direct complement restriction of flavivirus infection requires glycan recognition by mannose-binding lectin. Cell Host Microbe 2010;8:186-195.

52 Diamond MS, Roberts TG, Edgil D, Lu B, Ernst J, Harris E: Modulation of dengue virus infection in human cells by $\alpha-, \beta$-, and $\gamma$-interferons. J Virol 2000;74:4957-4966.

53 Daffis S, Szretter KJ, Schriewer J, Li J, Youn S, Errett J, Lin TY, Schneller S, Zust R, Dong $\mathrm{H}$, et al: 2'-O-methylation of the viral mRNA cap evades host restriction by IFIT family members. Nature 2010;468:452-456.

-54 Fredericksen BL, Smith M, Katze MG, Shi PY, Gale M Jr: The host response to West Nile virus infection limits viral spread through the activation of the interferon regulatory factor 3 pathway. J Virol 2004;78:7737-7747.

55 Liu WJ, Wang XJ, Clark DC, Lobigs M, Hall RA, Khromykh AA: A single amino acid substitution in the West Nile virus nonstructural protein NS2A disables its ability to inhibit $\alpha / \beta$ interferon induction and attenuates virus virulence in mice. J Virol 2006;80: 2396-2404.

56 Laurent-Rolle M, Boer EF, Lubick KJ, Wolfinbarger JB, Carmody AB, Rockx B, Liu W, Ashour J, Shupert WL, Holbrook MR, et al: The NS5 protein of the virulent West Nile virus NY99 strain is a potent antagonist of type I interferon-mediated JAK-STAT signaling. J Virol 2010;84:3503-3515.

57 Evans JD, Seeger C: Differential effects of mutations in NS4B on West Nile virus replication and inhibition of interferon signaling. J Virol 2007;81:11809-11816.

58 Arjona A, Ledizet M, Anthony K, Bonafé N, Modis Y, Town T, Fikrig E: West Nile virus envelope protein inhibits dsRNA-induced innate immune responses. J Immunol 2007; 179:8403-8409.

59 Wilson JR, de Sessions PF, Leon MA, Scholle F: West Nile virus nonstructural protein 1 inhibits TLR3 signal transduction. J Virol 2008;82:8262-8271.

60 Baronti C, Sire J, de Lamballerie X, Quérat G: Nonstructural NS1 proteins of several mosquito-borne flavivirus do not inhibit TLR3 signaling. Virology 2010;404:319-330.

61 Chung KM, Liszewski MK, Nybakken G, Davis AE, Townsend RR, Fremont DH, Atkinson JP, Diamond MS: West Nile virus nonstructural protein NS1 inhibits complement activation by binding the regulatory protein factor H. Proc Natl Acad Sci USA 2006;103:19111-19116. 
-62 Avirutnan P, Fuchs A, Hauhart RE, Somnuke P, Youn S, Diamond MS, Atkinson JP: Antagonism of the complement component C4 by flavivirus nonstructural protein NS1. J Exp Med 2010;207:793-806.

63 Juul-Madsen HR, Viertlboeck B, Smith AL, Göbel TWF: Avian innate immune responses; in Davidson F, Kaspers B, Schat KA (eds): Avian Immunology. London, Academic Press, 2008, pp 129-158.

64 Diamond MS, Shrestha B, Marri A, Mahan D, Engle M: B cells and antibody play critical roles in the immediate defense of disseminated infection by West Nile encephalitis virus. J Virol 2003;77:2578-2586.

65 Diamond MS, Sitati EM, Friend LD, Higgs S, Shrestha B, Engle M: A critical role for induced IgM in the protection against West Nile virus infection. J Exp Med 2003;198: 1853-1862.

-66 Shrestha B, Ng T, Chu HJ, Noll M, Diamond MS: The relative contribution of antibody and CD8+ $\mathrm{T}$ cells to vaccine immunity against West Nile encephalitis virus. Vaccine 2008;26:2020-2033.

-67 Oliphant T, Nybakken GE, Austin SK, Xu Q, Bramson J, Loeb M, Throsby M, Fremont DH, Pierson TC, Diamond MS: Induction of epitope-specific neutralizing antibodies against West Nile virus. J Virol 2007;81: 11828-11839.

68 Throsby M, Geuijen C, Goudsmit J, Bakker AQ, Korimbocus J, Kramer RA, Clijstersvan der Horst $M$, de Jong M, Jongeneelen M, et al: Isolation and characterization of human monoclonal antibodies from individuals infected with West Nile virus. J Virol 2006;80:6982-6992.

69 Mehlhop E, Nelson S, Jost CA, Gorlatov S, Johnson S, Fremont DH, Diamond MS, Pierson TC: Complement protein $\mathrm{Clq}$ reduces the stoichiometric threshold for antibodymediated neutralization of West Nile virus. Cell Host Microbe 2009;6:381-391.

70 Chung KM, Thompson BS, Fremont DH, Diamond MS: Antibody recognition of cell surface-associated NS1 triggers $\mathrm{Fc}-\gamma$ receptormediated phagocytosis and clearance of West Nile virus-infected cells. J Virol 2007; 81:9551-9555.

71 Douglas MW, Kesson AM, King NJ: CTL recognition of west Nile virus-infected fibroblasts is cell cycle dependent and is associated with virus-induced increases in class I MHC antigen expression. Immunology 1994;82:561-570.

72 Shrestha B, Diamond MS: Role of CD8+ T cells in control of West Nile virus infection. J Virol 2004;78:8312-8321.

73 Sitati EM, Diamond MS: CD4+ T-cell responses are required for clearance of West Nile virus from the central nervous system. J Virol 2006;80:12060-12069.
74 Wang Y, Lobigs M, Lee E, Müllbacher A: Exocytosis and Fas mediated cytolytic mechanisms exert protection from West Nile virus induced encephalitis in mice. Immunol Cell Biol 2004;82:170-173.

75 Pruitt AA: Central nervous system infections in cancer patients. Semin Neurol 2004; 24:435-452.

76 Wang Y, Lobigs M, Lee E, Müllbacher A: CD8+ T cells mediate recovery and immunopathology in West Nile virus encephalitis. J Virol 2003;77:13323-13334.

77 Glass WG, Lim JK, Cholera R, Pletnev AG, Gao JL, Murphy PM: Chemokine receptor CCR5 promotes leukocyte trafficking to the brain and survival in West Nile virus infection. J Exp Med 2005;202:1087-1098.

78 Klein RS, Lin E, Zhang B, Luster AD, Tollett J, Samuel MA, Engle M, Diamond MS: Neuronal CXCL10 directs CD8+ T-cell recruitment and control of West Nile virus encephalitis. J Virol 2005;79:11457-11466.

79 Sitati E, McCandless EE, Klein RS, Diamond MS: CD40-CD40 ligand interactions promote trafficking of CD8+ T cells into the brain and protection against West Nile virus encephalitis. J Virol 2007;81:9801-9811.

80 Diamond MS: Virus and host determinants of West Nile virus pathogenesis. PLoS Pathog 2009; 5:e1000452.

-81 Lanteri MC, O’Brien KM, Purtha WE, Cameron MJ, Lund JM, Owen RE, Heitman JW, Custer B, Hirschkorn DF, Tobler LH, et al: Tregs control the development of symptomatic West Nile virus infection in humans and mice. J Clin Invest 2009;119:3266-3277.

82 Vaughan K, Greenbaum J, Blythe M, Peters B, Sette A: Meta-analysis of all immune epitope data in the Flavivirus genus: inventory of current immune epitope data status in the context of virus immunity and immunopathology. Viral Immunol 2010;23:259-284.

83 McMurtrey CP, Lelic A, Piazza P, Chakrabarti AK, Yablonsky EJ, Wahl A, Bardet W, Eckerd A, Cook RL, Hess R, et al: Epitope discovery in West Nile virus infection: Identification and immune recognition of viral epitopes. Proc Natl Acad Sci USA 2008;105: 2981-2986.

$>84$ Kim S, Li L, McMurtrey CP, Hildebrand WH, Weidanz JA, Gillanders WE, Diamond MS, Hansen TH: Single-chain HLA-A2 MHC trimers that incorporate an immundominant peptide elicit protective T-cell immunity against lethal West Nile virus infection. J Immunol 2010;184:4423-4430.

85 Brien JD, Uhrlaub JL, Hirsch A, Wiley CA, Nikolich-Zugich J: Key role of T-cell defects in age-related vulnerability to West Nile virus. J Exp Med 2009;206:2735-2745.

86 Gardner IA, Wong SJ, Ferraro GL, Balasuriya UB, Hullinger PJ, Wilson WD, Shi PY, MacLachlan NJ: Incidence and effects of West Nile virus infection in vaccinated and unvaccinated horses in California. Vet Res 2007;38:109-116.
$87 \mathrm{Ng}$ T, Hathaway D, Jennings N, Champ D, Chiang YW, Chu HJ: Equine vaccine for West Nile virus. Dev Biol (Basel) 2003;114: 221-227.

-88 Samina I, Khinich Y, Simanov M, Malkinson M: An inactivated West Nile virus vaccine for domestic geese - efficacy study and a summary of 4 years of field application. Vaccine 2005;23:4955-4958.

89 Guy B, Guirakhoo F, Barban V, Higgs S, Monath TP, Lang J: Preclinical and clinical development of YFV 17D-based chimeric vaccines against dengue, West Nile and Japanese encephalitis viruses. Vaccine 2010;28: 632-649.

90 El Garch H, Minke JM, Rehder J, Richard S, Edlund Toulemonde C, Dinic S, Andreoni C, Audonnet JC, Nordgren R, Juillard V: A West Nile virus (WNV) recombinant canarypox virus vaccine elicits WNV-specific neutralizing antibodies and cell-mediated immune responses in the horse. Vet Immunol Immunopathol 2008;123:230-239.

91 Davis BS, Chang GJ, Cropp B, Roehrig JT, Martin DA, Mitchell CJ, Bowen R, Bunning ML: West Nile virus recombinant DNA vaccine protects mouse and horse from virus challenge and expresses in vitro a noninfectious recombinant antigen that can be used in enzyme-linked immunosorbent assays. J Virol 2001;75:4040-4047.

92 Wang T, Anderson JF, Magnarelli LA, Wong SJ, Koski RA, Fikrig E: Immunization of mice against West Nile virus with recombinant envelope protein. J Immunol 2001;167: 5273-5277.

-93 Martina BE, Koraka P, van den Doel P, van Amerongen G, Rimmelzwaan GF, Osterhaus AD: Immunization with West Nile virus envelope domain III protects mice against lethal infection with homologous and heterologous virus. Vaccine 2008;26:153-157.

94 Lieberman MM, Nerurkar VR, Luo H, Cropp B, Carrion R Jr, de la Garza M, Coller BA, Clements D, Ogata S, et al: Immunogenicity and protective efficacy of a recombinant subunit West Nile virus vaccine in rhesus monkeys. Clin Vaccine Immunol 2009; 16:1332-1337.

95 Spohn G, Jennings GT, Martina BE, Keller I, Beck M, Pumpens P, Osterhaus AD, Bachmann MF: A VLP-based vaccine targeting domain III of the West Nile virus E protein protects from lethal infection in mice. Virol J 2010;7:146.

$\checkmark 96$ Bellier B, Huret C, Miyalou M, Desjardins D, Frenkiel MP, Despres P, Tangy F, Dalba C, Klatzmann D: DNA vaccines expressing retrovirus-like particles are efficient immunogens to induce neutralizing antibodies. Vaccine 2009;27:5772-5780. 
\$97 Demento SL, Bonafé N, Cui W, Kaech SM, Caplan MJ, Fikrig E, Ledizet M, Fahmy TM: TLR9-targeted biodegradable nanoparticles as immunization vectors protect against West Nile encephalitis. J Immunol 2010;185:2989-2997.

-98 Widman DG, Ishikawa T, Giavedoni LD, Hodara VL, Garza Mde L, Montalbo JA, Travassos Da Rosa AP, Tesh RB, Patterson JL, Carrion R Jr, Bourne N, Mason PW: Evaluation of RepliVAX WN, a single-cycle flavivirus vaccine, in a non-human primate model of West Nile virus infection. Am J Trop Med Hyg 2010;82:1160-1167.

-99 Schlick P, Kofler RM, Schittl B, Taucher C, Nagy E, Meinke A, Mandl CW: Characterization of West Nile virus live vaccine candidates attenuated by capsid deletion mutations. Vaccine 2010;28:5903-5909.
00 Martin JE, Pierson TC, Hubka S, Rucker S, Gordon IJ, Enama ME, Andrews CA, Xu Q, Davis BS, Nason M, et al: A West Nile virus DNA vaccine induces neutralizing antibody in healthy adults during a phase 1 clinical trial. J Infect Dis 2007;196:17321740.

101 Dunn MD, Rossi SL, Carter DM, Vogt MR, Mehlhop E, Diamond MS, Ross TM: Enhancement of anti-DIII antibodies by the C3d derivative $\mathrm{P} 28$ results in lower viral titers and augments protection in mice. Virol J 2010;7:95.
102 Ramanathan MP, Kutzler MA, Kuo YC, Yan J, Liu H, Shah V, Bawa A, Selling B, Sardesai NY, Kim JJ, Weiner DB: Coimmunization with an optimized IL15 plasmid adjuvant enhances humoral immunity via stimulating B cells induced by genetically engineered DNA vaccines expressing consensus JEV and WNV E DIII. Vaccine 2009; 27:4370-4380.

103 Kutzler MA, Weiner DB:DNA vaccines: ready for prime time? Nat Rev Genet 2008; 9:776-788.

104 Schneeweiss A, Chabierski S, Salomo M, Al-Robayi S, Delaroque N, Grunwald T, Bürki K, Liebert UG, Ulbert S: A DNA vaccine encoding the $\mathrm{E}$ protein of West $\mathrm{Nile} \mathrm{Vi}$ rus is protective and can be boosted by recombinant domain DIII Vaccine. Vaccine, in press. 